\title{
Isoleucine Measurement
}

National Cancer Institute

\section{Source}

National Cancer Institute. Isoleucine Measurement. NCI Thesaurus. Code C103410.

The determination of the amount of the isoleucine in a sample. 